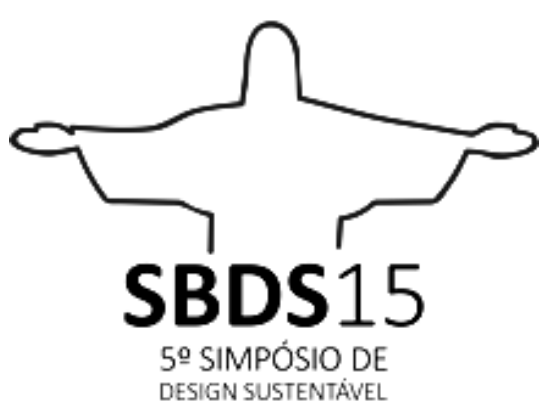

Rio de Janeiro, 11 de novembro a 13 de novembro de 2015

\title{
ESTUDO DE ALTERNATIVAS PARA MELHORIA DO DESEMPENHO ENERGÉTICO DE UMA EDIFICAÇÃO COMERCIAL EM SÃO PAULO
}

\author{
Thiago dos Santos Ferreira \\ Anarita Bueno Buoro \\ Universidade Cidade de São Paulo (UNICID) / \\ Instituto Brasileiro de Educação Continuada (INBEC) \\ thiagoferreira.arq@gmail.com \\ ritabuoro@gmail.com
}

\begin{abstract}
Resumo: Diante da importância de se projetar e reabilitar edificações na busca da redução do consumo de energia, este trabalho concentrou-se em avaliar diversas estratégias que pudessem reduzir o dispêndio de energia de um determinado edifício comercial situado em São Paulo, capital. Como objeto de estudo, foi escolhido um edifício existente e representativo dentro do contexto imobiliário do município para a proposta de retrofit. Tal análise foi efetuada levando em conta técnicas comerciais utilizadas com frequência no mercado imobiliário, com o auxílio de um / paramétrico de simulação. As informações inseridas neste programa foram levantadas in loco e pesquisadas em normas. Em consonância com os dados climáticos, um cenário base foi estabelecido para que, posteriormente, novos cenários com estratégias de melhoria pudessem ser aplicados ao estudo de caso. Com base nos cenários obtidos a partir das simulações das estratégias, avaliaram-se os impactos no consumo de energia anual. Para cada proposta, examinaram-se as qualidades e vulnerabilidades para que o produto final tivesse a melhor relação custo-benefício.
\end{abstract}

Palavras-chave: Eficiência energética, simulação termo-energética, retrofit, desempenho térmico, edificações comerciais.

Abstract: Bearing in mind the importance to design and refurbish buildings with low impact and energy consumption, this work concentrated on evaluating various strategies that could mitigate and reduce the energy expenditure of a certain building. As for the case study, a commercial building that was representative within the real estate market of the city was chosen. This analysis was performed taking into account techniques used frequently in the retrofit market, with the aid of a parametric simulation software. The input data used in the software was collected with the facilities managers of the case study and researched in international regulations. In line with the climatic data, a base scenario was established, so that the improvement strategies were able to be simulated. Based on the scenarios obtained from the simulations of the strategies 
proposed, the impacts on annual energy consumption as well as on the lighting and air conditioning systems were evaluated. The techniques were examined in order to elucidate the qualities and vulnerabilities of each of them.

Key-words: Energy efficiency, parametric simulation, retrofit, thermal performance, commercial buildings.

\section{INTRODUÇÃO}

O desenvolvimento das sociedades, principalmente a partir da Revolução Industrial, sempre esteve ligado ao alto consumo de recursos energéticos. A forma desmedida com que esses insumos foram sendo consumidos, desde o crescimento técnico cientifico da humanidade, tem gerado graves problemas ambientais, como o aquecimento global. Para Serafin (2010), o crescente aumento no consumo de energia elétrica é reflexo do crescimento econômico de um país e dos hábitos de vida contemporâneos.

Esse crescimento tende a aumentar, se considerarmos que a maior parte da população mundial viverá nos grandes centros urbanos nas próximas décadas. Devido às condições hidrológicas desfavoráveis do Brasil em 2013, houve uma redução na oferta de energia hidráulica nesse período. Esse cenário, juntamente com o aumento do consumo final de eletricidade do país, de 3,6\%, com destaque para os setores residencial e comercial, favoreceu a expansão da geração térmica, especialmente das usinas movidas a carvão mineral (EPE 2014).

Ao redor do mundo, estima-se que $30 \%$ a $40 \%$ da energia primária seja utilizada em edificações, fator que evidencia a construção civil como um setor chave para promover um desenvolvimento sustentável e com baixo consumo energético (UNEP, 2007). Sendo assim, a realidade energética e ambiental demonstra a necessidade de tanto a produção quanto a operação dos edifícios serem adaptadas às novas regulamentações energéticas e ambientais (SANTANA, 2006). A redução do consumo energético através da renovação de edificações existentes é uma das opções mais atraentes e de baixo custo para diminuir as emissões de dióxido de carbono (CE, 2012). Segundo Guzenski (2011), do mesmo modo que a economia e a sociedade avançam, as edificações deveriam ser melhoradas para suportar a possível demanda de energia excedente causada pela má qualidade das envoltórias e das construções em si. Uma análise fundamentada das propriedades físicas dos materiais e do tipo de clima no qual a edificação será inserida pode gerar grandes ganhos de eficiência (MELO 2007). Com o crescente aumento de normas de eficiência energética no mundo, assim como das certificações ambientais no Brasil, principalmente no setor de edifícios corporativos e comerciais, tais como AQUA-HQE, LEED, PBE EDIFICA, entre outros, abre-se um precedente para se buscar edificações mais eficientes.

Em virtude da alta competitividade do mercado, principalmente na região de São Paulo, os proprietários de prédios existentes tendem a reavaliar as suas gestões e até mesmo investir em uma renovação para manterem seus patrimônios atualizados e atrativos. Em razão desta demanda, ferramentas computacionais para auxiliar os projetistas e tomadores de decisão vêm sendo utilizadas com frequência. Os softwares de simulação permitem estimar o consumo de energia de uma edificação existente de acordo com as suas características, bem como a partir da proposição de novas soluções tecnológicas e arquitetônicas, visando a melhoria do seu desempenho energético.

Considerando este contexto histórico e mercadológico, esta pesquisa busca estudar o potencial de conservação de energia de uma edificação comercial, localizada em São Paulo, através da utilização de um software paramétrico de simulação termo- 
energética.

\section{OBJETIVO}

Elaborar um projeto de retrofit energético de um edifício comercial na cidade de São Paulo, considerando a viabilidade e tecnologia adequada para a implantação da proposta. Para isto, os dados do projeto e ocupação foram analisados e embasaram as propostas de substituição de materiais e tecnologias, buscando um entendimento plausível e factível de como elas poderiam aprimorar a performance energética do estudo de caso a partir da simulação termo-energética destas variáveis.

\section{METODOLOGIA}

Estabeleceu-se uma metodologia para se avaliar a edificação sob a ótica do consumo energético através do levantamento das informações técnico-construtivas, de entrevistas com os atuais administradores do edifício, projetistas responsáveis pelos projetos complementares, e através de simulações termo-energéticas utilizando os softwares Design Builder e Ecotect.

A primeira etapa da pesquisa foi iniciada através de registros fotográficos da edificação, de seus espaços interiores e instalações. Posteriormente, entrevistou-se a equipe responsável pela operação do edifício a fim de entender o seu funcionamento, seguido pelos indivíduos responsáveis pelo sistema de automação.

Dados sobre o consumo de energia, funcionamento dos equipamentos, modus operandi dos sistemas e projetos foram coletados com estas equipes e alguns dos projetistas da edificação. Uma unidade, localizada no quarto pavimento, também foi visitada de modo a realizar uma análise real da iluminação natural do projeto. A Figura 1 elucida o procedimento aplicado neste trabalho.

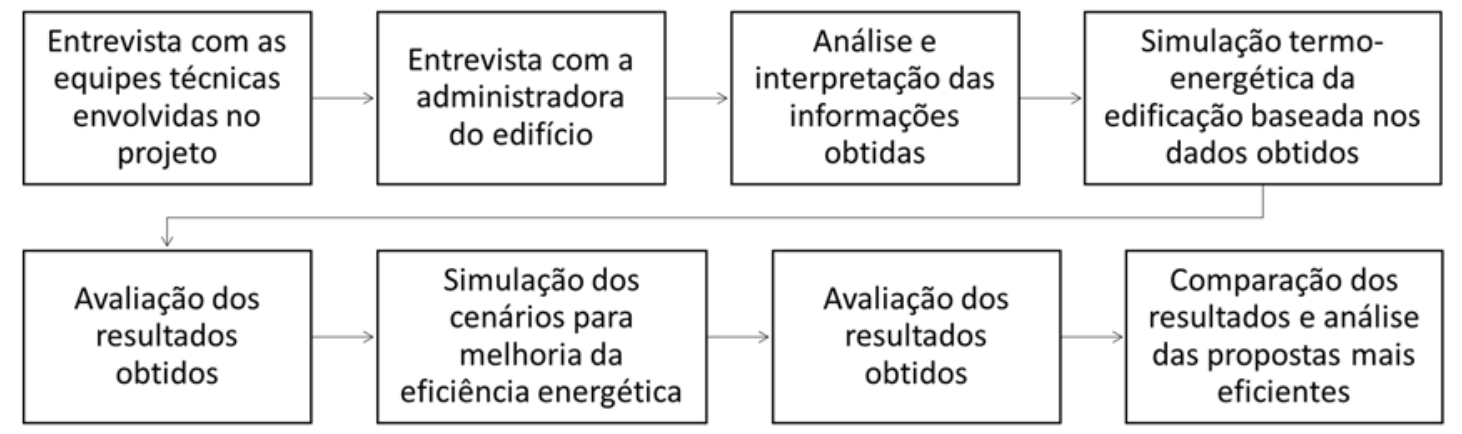

Figura 1 - Fluxograma da metodologia aplicada a pesquisa.

Fonte: Elaboração própria.

\section{AVALIAÇÃO DO EDIFÍCIO CONSTRUÍDO}

\subsection{Aspectos Gerais}

O objeto de estudo é uma edificação comercial localizada próxima a região da Berrini, Zona Sul de São Paulo, conforme Figura 2. A torre foi projetada em 2001 e teve sua operação iniciada em 2003. Possui 16 andares comerciais, com 15 pavimentos tipo, os quais possuem $865 \mathrm{~m}^{2}$ de área privativa cada e uma cobertura de e $1.080 \mathrm{~m}^{2} \mathrm{com}$ mezanino. Há um espaço disponível no térreo para um restaurante e uma loja. $O$ teatro localiza-se no 1 o subsolo e possui uma área total de $780 \mathrm{~m}^{2}$. Por fim, a área reservada para o restaurante e eventos tem $441 \mathrm{~m}^{2}$, com pé-direito triplo e acesso independente. Há também cinco subsolos para acomodar o estacionamento e a infraestrutura. 


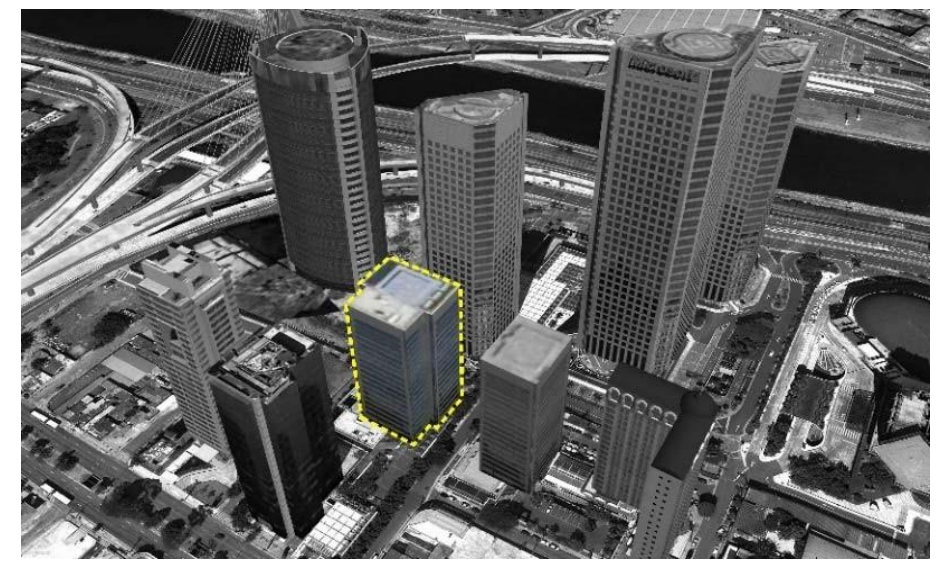

Figura 2 - Localização do objeto de estudo.

Fonte: Elaboração própria sobre imagem do Google Earth.

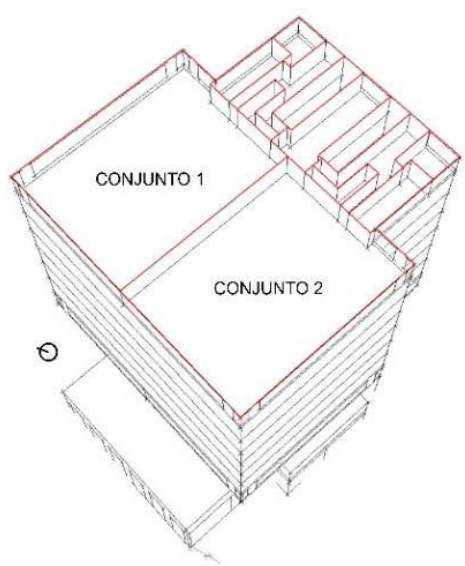

Figura 3 - Planta baixa tipo. Fonte: Elaboração própria.
O entorno imediato é composto por um complexo de edifícios comerciais (Figura 2), cujas alturas são iguais ou maiores do que da torre estudada. Tendo em vista essa situação, os edifícios lindeiros foram modelados a fim de verificar a incidência do sombreamento promovido por eles sobre as edificações vizinhas, as quais afetam consideravelmente a incidência solar sobre a edificação em estudo, já que a mesma se encontra circundada por obstruções em todas as orientações.

O diagrama solar da Figura 4a, refere-se a fachada nordeste, azimute $18 \%$, onde encontra-se 0 acesso a torre. O sombreamento dos edifícios vizinhos afeta principalmente os meses mais frios, onde a radiação pode ser necessária para o aquecimento dos ambientes. A Figura $4 b$, enfatiza a baixa incidência de sol sobre a fachada de azimute 72을 indicando que a altura e disposição das torres 1,2 e 6 impactam diretamente no nível de iluminação dos pavimentos. A Figura 4c ilustra que há incidência solar direta apenas entre Setembro e Novembro na fachada sul, azimute $162^{\circ}$, no intervalo de tempo entre $13 \mathrm{~h}$ e $18 \mathrm{~h}$. Por fim, a fachada de azimute 108ㅇ, Figura 4d, recebe um bom nível de radiação durante as primeiras horas da manhã.

\subsubsection{Parâmetros da modelagem do edifício em software paramétrico de simulação}

\subsubsection{Materiais e estrutura}

Os materiais que compõem a edificação (Tabela 1 ) foram extraídos do levantamento in loco, do projeto executivo de arquitetura e do memorial descritivo. As paredes externas são constituídas por um revestimento de granito na face externa, uma camada de ar, concreto e reboco interno pintado. O sistema de entrepiso é composto 
por forro de gesso, uma espessa camada de ar, laje de concreto e piso elevado. A cobertura da última laje é formada por um forro de gesso, uma camada de ar, laje de concreto, impermeabilização com manta asfáltica e uma camada de regularização.

Tabela 1 - Características térmicas dos materiais.

\begin{tabular}{lccc}
\hline Elementos & Espessura $(\mathrm{cm})$ & $\begin{array}{c}\text { Transmitância } \\
\text { térmica U } \\
\left(\mathrm{W} / \mathrm{m}^{2} . \mathrm{K}\right)\end{array}$ & $\begin{array}{l}\text { Resistência } \\
\text { térmica } \mathrm{R} \\
\left(\mathrm{m}^{2} . \mathrm{K} / \mathrm{W}\right)\end{array}$ \\
\hline Parede externa & 31 & 2.10 & 0.475 \\
\hline Parede interna & 19 & 1.24 & 0.80 \\
\hline Piso intermediário & 119 & 0.78 & 1.27 \\
\hline Cobertura & 27 & 1.67 & 0.60 \\
\hline
\end{tabular}

Fonte: Elaboração própria com base nas informações do software Design Builder, projeto executivo de arquitetura e memorial descritivo.

\subsubsection{Propriedades térmicas do vidro instalado}

Os vidros das esquadrias externas são do tipo laminado refletivo na cor azul acinzentada, espessura total de $9 \mathrm{~mm}$. Através de uma entrevista com o fabricante, constatou-se que esse tipo de vidro não é mais fabricado, portanto os valores das propriedades térmicas foram estimados pelo próprio fornecedor, de acordo com a Tabela 2.

Tabela 2 - Características térmicas dos materiais.

\begin{tabular}{lcccc} 
Tipo de vidro & $\begin{array}{c}\text { Espessura } \\
(\mathrm{mm})\end{array}$ & $\begin{array}{c}\text { Transmitância térmica } \\
\cup\left(\mathrm{W} / \mathrm{m}^{2} . \mathrm{K}\right)\end{array}$ & $\begin{array}{c}\text { Transmissão } \\
\text { luminosa }\end{array}$ & Fator solar (SHGC) \\
\hline Laminado & 9 & 5.70 & 0.29 & 0.37 \\
\hline
\end{tabular}

Fonte: Elaboração própria com base nas informações dos fabricantes.

\subsubsection{Características dos sistemas de ar condicionado e iluminação}

O sistema de ar condicionado que atende aos conjuntos comerciais é do tipo expansão indireta, composto por três chillers com condensação a ar, capacidade de 192,5 TR cada, com coeficiente de performance (COP) de 2,92. A distribuição do ar nos pavimentos tipo acontece através de dois fan-coils, que atendem aos dois conjuntos comerciais, separadamente. Ambos são controlados pela automação predial e dotados de variadores de frequência. $O$ projeto original de luminotécnica previu, para o ambiente principal de cada unidade, a instalação de lâmpadas do tipo fluorescente tubular T8. Para os ambientes de transição, assim como banheiros e copa, o projeto pressupõe a colocação de lâmpadas fluorescentes compactas.

\subsubsection{Cargas internas da edificação}

Para a carga de iluminação adotou-se a taxa de $12 \mathrm{~W} / \mathrm{m}^{2}$, com fração radiante igual a 37 \% e fração visível (eficiência da lâmpada) de $18 \%$, com base nas recomendações da ASHRAE (2005). Para a carga de equipamentos adotou-se a taxa de $16 \mathrm{~W} / \mathrm{m}^{2}$ com fração radiante de $30 \%$, de acordo com a ASHRAE (2005). O valor de densidade de ocupação utilizado foi de 0,10 pessoas $/ \mathrm{m}^{2}$, o mesmo adotado pelo projetista de ar condicionado para efetuar os cálculos da demanda de resfriamento dos ambientes internos. A taxa de infiltração é um parâmetro difícil de ser medido ou adquirido. Com isso utilizaram-se 
dados extraídos da norma ASHRAE (2005). O valor empregado foi de 0,50 ACH (Air Changes per Hour).

\subsubsection{Padrão de uso}

O valor de padrão de uso adotado para o funcionamento da edificação foi de $10 \mathrm{~h}$. Este padrão condiz com os horários de ocupação convencionais de uma edificação comercial durante a semana, sendo o horário inicial das atividades às $8 \mathrm{~h}$ e o final às $18 \mathrm{~h}$. Não foi considerada nenhuma ocupação para os finais de semana. A Tabela 3 resume os parâmetros utilizados na simulação.

Tabela 3 - Parâmetros utilizados na simulação termo-energética do objeto de estudo.

\begin{tabular}{lc}
\hline Parâmetro & Valor adotado \\
\hline Clima & São Paulo - SP \\
\hline Padrão de ocupação & 10 horas (8h às 18h) \\
\hline Densidade de carga de equipamentos $\left(\mathrm{W} / \mathrm{m}^{2}\right)$ & 16 (ASHRAE) \\
\hline Densidade de carga de iluminação $\left(\mathrm{W} / \mathrm{m}^{2}\right)$ & 12 (ASHRAE) \\
\hline Infiltração $(\mathrm{ACH})$ & 0,5 \\
\hline COP do sistema de ar condicionado & 2,92 \\
\hline
\end{tabular}

Fonte: Elaborado pelo autor, com base na pesquisa realizada.

\subsection{Análise dos resultados simulados: condição atual do consumo de energia}

Os consumos anuais obtidos através da simulação relacionados à iluminação, equipamentos e ar condicionado foram de 360,87MWh, 481,16MWh e 371,87MWh, respectivamente. O percentual de cada um dos sistemas em relação ao consumo anual de energia pode ser visto na Figura 6.

Possivelmente, o consumo de energia reduzido do ar condicionado com relação ao total, se comparado a bibliografia estudada, é devido ao sombreamento das fachadas, que como apresentado na Figura 4, reduz significativamente o ganho de calor pela envoltória. O edifício apresenta um consumo anual real de energia, referente as áreas ocupadas, de 1213,9 MWh ano, ou $98,97 \mathrm{kWh} / \mathrm{m}^{2} /$ ano (Figura 7). É perceptível a redução do consumo durante o período de temperaturas mais amenas (junho, julho e

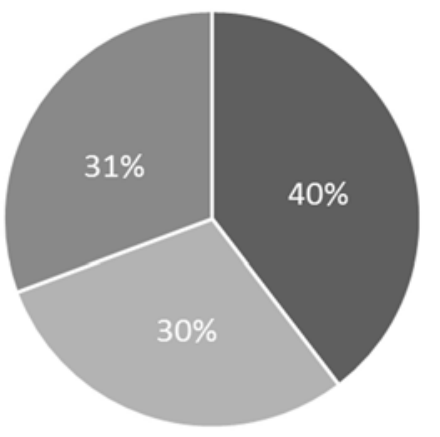

- Equipamentos = Iluminação = Ar condicionado

Figura 6 - Consumo de energia por usos finais do modelo simulado do estudo de caso.

Fonte: Elaboração própria. 
agosto), apesar do sistema de ar condicionado ser acionado com menor frequência e provavelmente com temperaturas de setpoint mais elevadas, se comparadas com os meses mais quentes.

O fluxo energético, demonstrado na Figura 8, analisado em um ano típico, sugere que há mais perda de energia do que ganho através dos materiais instalados. Percebe- se que os vidros contribuem de forma significativa, tanto no sentido de perda de energia, de maio a julho, quanto no sentido de ganho energético, durante os meses de janeiro e fevereiro.

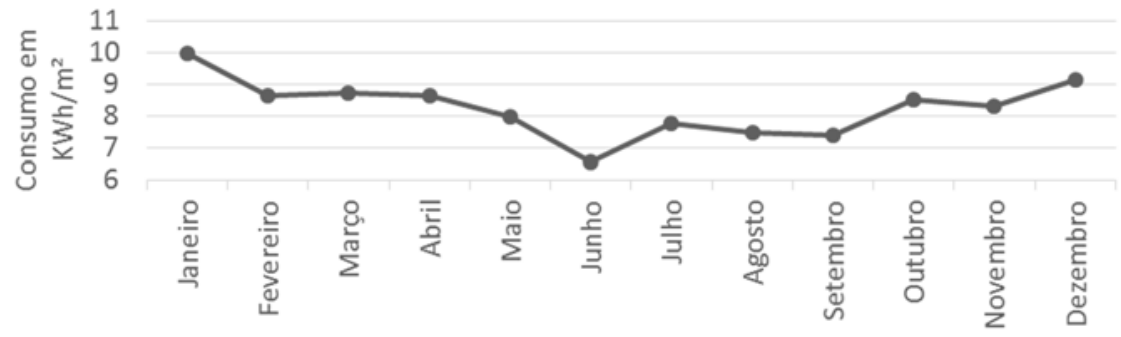

Figura 7 - Consumo de energia do objeto de estudo no ano de 2002.

Fonte: Elaboração própria com dados de saída do programa Design Builder.

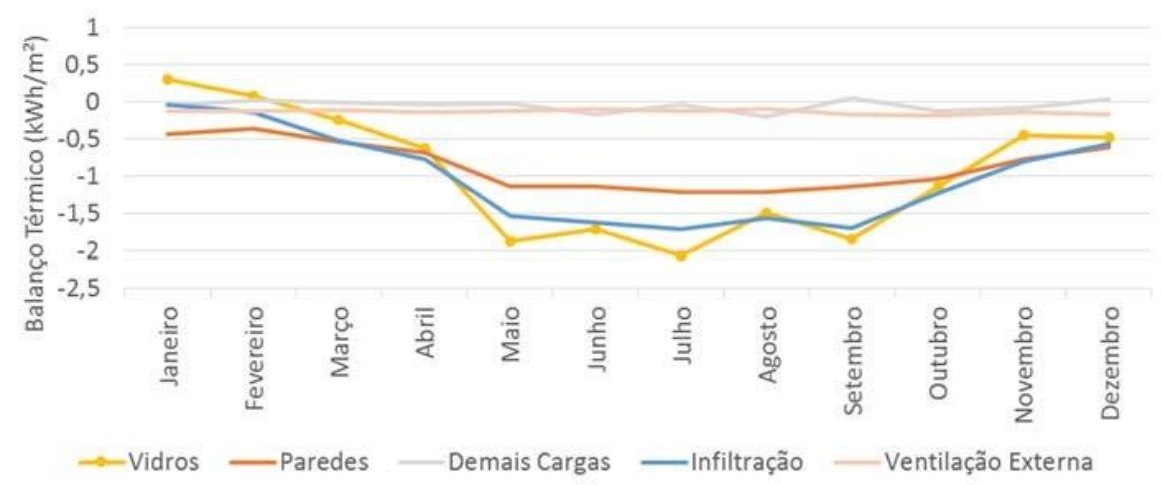

Figura 8 - Balanço térmico da do objeto de estudo em um ano típico.

Fonte: Elaboração própria com dados de saída do programa Design Builder.

Ao analisar os ganhos internos ao longo do ano (Figura 9), percebe-se que as cargas internas, que não dependem das condições climáticas, contribuem de forma expressiva para o consumo energético.

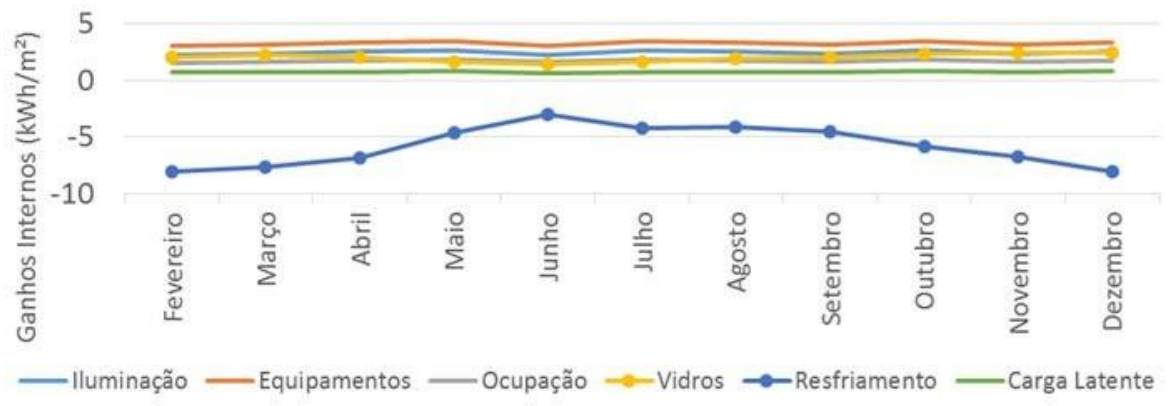

Figura 9 - Ganhos internos do objeto de estudo.

Fonte: Elaboração própria com dados de saída do programa Design Builder. 


\section{Avaliação dos cenários para melhoria do desempenho energético}

\subsection{Substituição dos vidros}

O tipo de vidro pode elevar ou diminuir o consumo de uma edificação radicalmente. Sendo assim, analisaram-se diversas composições de vidro de modo a efetuar um comparativo. Os dados dos vidros foram adquiridos através de diferentes fabricantes e ilustram as diversas composições possíveis (Tabela 4).

Tabela 4 - Dados comparativos dos vidros analisados.

\begin{tabular}{lllll}
\hline Tipo de vidro & $\begin{array}{c}\text { Espessura } \\
(\mathrm{mm})\end{array}$ & $\begin{array}{c}\text { Transmitância } \\
\text { térmica U } \\
\left(\mathrm{W} / \mathrm{m}^{2} . \mathrm{K}\right)\end{array}$ & $\begin{array}{c}\text { Transmissão } \\
\text { luminosa }\end{array}$ & Fator solar (SHGC) \\
\hline GA118 Insulado & 25 & 1.76 & 0.37 & 0.30 \\
\hline GA119 Laminado & 8 & 5.52 & 0.35 & 0.36 \\
\hline GA119 Insulado & 24 & 1.71 & 0.38 & 0.31 \\
\hline GA120 Laminado & 8 & 5.6 & 0.50 & 0.33 \\
\hline GA120 Insulado & 24 & 1.5 & 0.49 & 0.27 \\
\hline
\end{tabular}

Fonte: Elaboração própria com base nas informações dos fabricantes.

De forma geral, a reposição do vidro atualmente instalado por outros de melhor desempenho não apresentou uma significativa redução no consumo de energia. Isso se deve ao sombreamento excessivo das fachadas ao longo do ano somado ao fato de que a carga térmica dominante é advinda dos equipamentos. O vidro GA 118, por exemplo, aumentou o consumo da edificação em 2,10\% ao ano. Esse fato se deve a sua composição, que diminui as trocas térmicas e evita que o calor gerado internamente seja perdido para o exterior, exigindo assim maior esforço do sistema de ar condicionado para resfriar os ambientes.

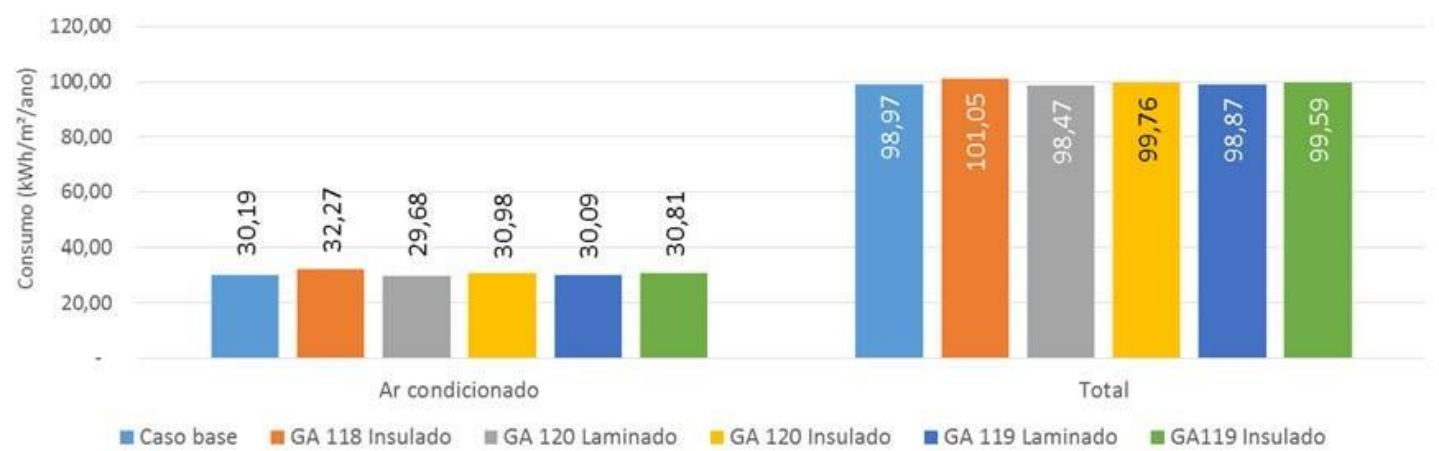

Figura 10 - Consumo de energia atrelado aos diferentes tipos de vidros.

Fonte: Elaboração própria com base nas informações dos fabricantes, utilizando o software Design Builder.

\subsection{Aplicação de película de controle solar sobre os vidros existentes}

As películas de controle solar têm sido utilizadas no mercado para diminuir o consumo de energia através da redução do calor excessivo recebido pela radiação solar, principalmente em edificações existentes, já que em alguns casos a troca dos vidros torna-se inviável, tanto por questões físicas quanto financeiras. Neste contexto, testou- se a aplicação de três modelos de películas na edificação, cujas características podem ser vistas na Tabela 5 . 
Tabela 5 - Dados comparativos das películas analisadas.

\begin{tabular}{|c|c|c|c|c|}
\hline Película & $\begin{array}{l}\text { Transmissão solar } \\
\text { total }\end{array}$ & $\begin{array}{c}\text { Transmitância } \\
\text { térmica U } \\
\left(\mathrm{W} / \mathrm{m}^{2} . \mathrm{K}\right.\end{array}$ & $\begin{array}{l}\text { Transmissão solar } \\
\text { direta }\end{array}$ & $\begin{array}{l}\text { Transmissão } \\
\text { luminosa }\end{array}$ \\
\hline
\end{tabular}

\begin{tabular}{lllll}
\hline Película 1 & 0.168 & 4.20 & 0.107 & 0.14 \\
\hline Película 2 & 0.187 & 4.73 & 0.122 & 0.157 \\
\hline Película 3 & 0.236 & 5.60 & 0.112 & 0.106 \\
\hline
\end{tabular}

Fonte: Elaboração própria com base nas informações dos fabricantes

As películas de controle solar 1 e 2 apresentaram uma redução significativa no consumo de energia se comparadas ao vidro de melhor desempenho, com uma diminuição no consumo de ar condicionado na ordem de 4,9\%. O filme que apresentou o melhor resultado foi o 3 . O consumo do ar condicionado atrelado a instalação desta película foi reduzido em 5,6\% (Figura 11). Apesar das películas apresentarem um bom resultado energético, é preciso avaliar a transmissão luminosa dos produtos, pois este fator pode comprometer o nível de iluminação natural dos ambientes.

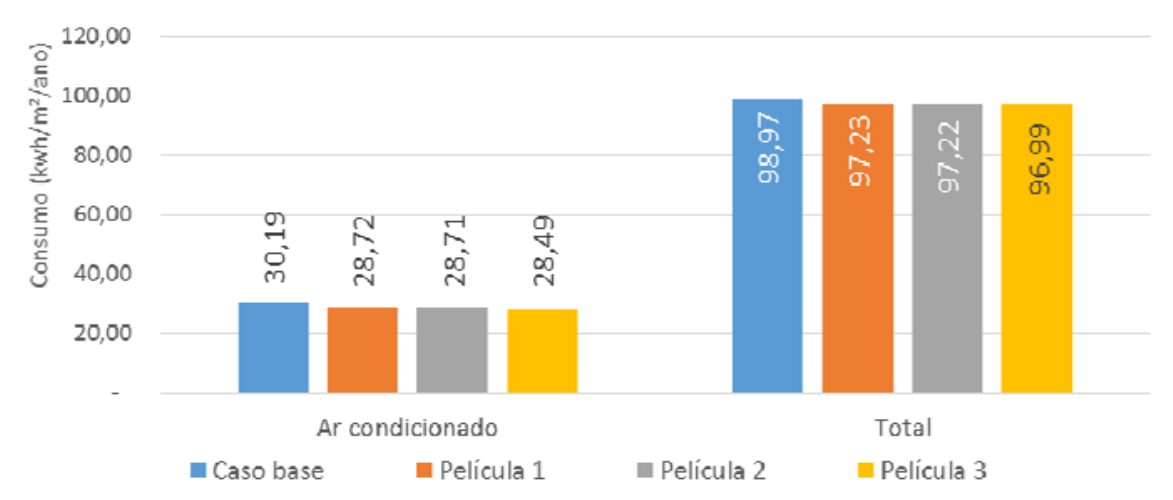

Figura 11 - Consumo de energia atrelado aos diferentes tipos de películas.

Fonte: Elaboração própria com base nas informações dos fabricantes, utilizando o software Design Builder.

\subsection{Instalação de persianas internas nos andares}

A instalação de elementos de proteção solar internos pode ser uma boa solução, pois é de fácil colocação e geralmente menos onerosa se comparada aos sistemas de sombreamento complexos e vidros de alta performance.

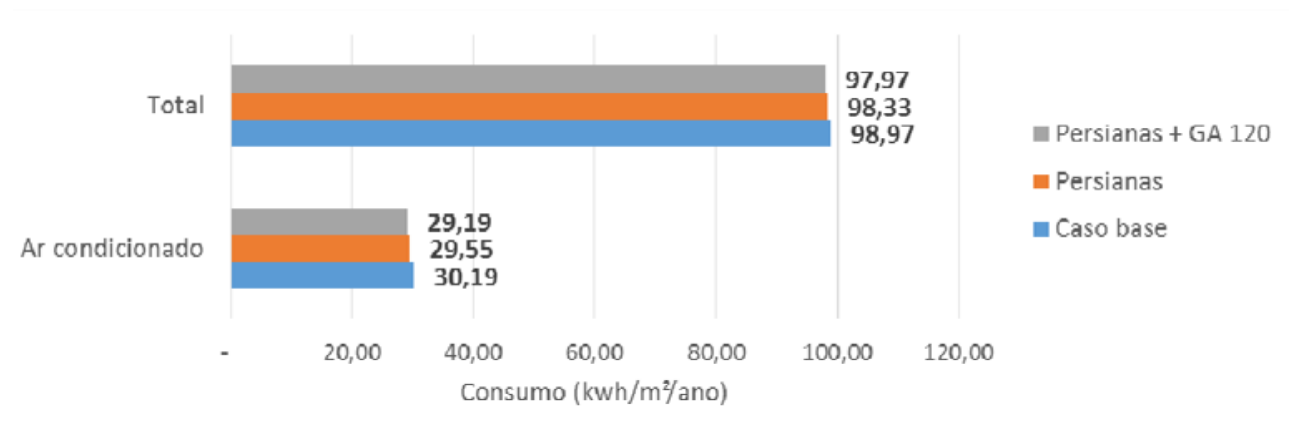

Figura 12 - Consumo de energia atrelado a instalação de persianas internas.

Fonte: Elaboração própria utilizando o software Design Builder.

Para esta simulação utilizaram-se persianas de alumínio com lâminas de $25 \mathrm{~cm}$, sempre fechadas, distantes $15 \mathrm{~cm}$ das esquadrias. O caso simulado com a colocação dos elementos de sombreamento internos representou uma diminuição no consumo de ar condicionado na ordem de $2,12 \%$, equivalente a um dispêndio total anual de energia de 1.203.794,50 kWh contra 1.213.901,09 kWh do caso base. Somando o vidro GA 120 a 
instalação das persianas, tem-se um consumo anual equivalente a 1.199.309,01 kWh, gerando assim uma economia de $0,65 \%$ ao ano com relação ao caso base.

\subsection{Substituição do sistema de iluminação}

Como alternativa de substituição às lâmpadas entregues com as unidades, propõe-se a utilização de lâmpadas do tipo LED (Figura 13). Segundo o Departamento de Energia dos Estados Unidos, as lâmpadas LED podem ser até sete vezes mais energeticamente eficientes que as lâmpadas incandescentes e gerar uma economia de até $80 \%$ na conta de energia. A lâmpada escolhida para a simulação foi o modelo LED840 da marca Philips, com entrega de pelo menos 450 lux contínuos sobre o plano de trabalho, cuja densidade de potência é de $7,19 \mathrm{~W} / \mathrm{m}^{2}$.

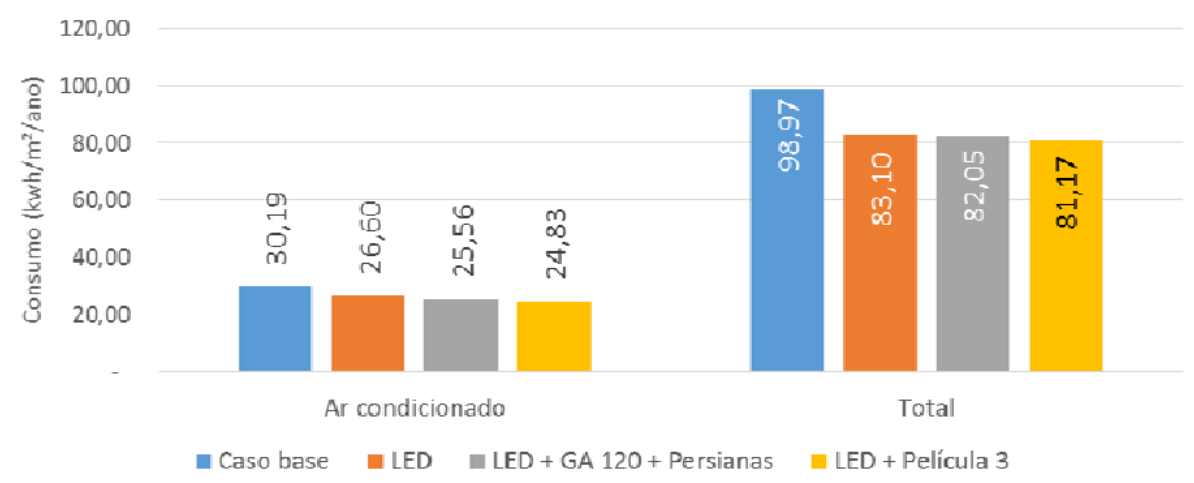

Figura 13 - Consumo de energia atrelado a instalação de lâmpadas LED.

Fonte: Elaboração própria com base nas informações dos fabricantes, utilizando o software Design Builder.

Analisando a implementação das lâmpadas LED, observa-se uma redução considerável no consumo anual do ar condicionado e total, $11,9 \%$ e $16,04 \%$ respectivamente. $O$ consumo anual do sistema de iluminação diminuiu de $360.870,04$ kWh para $210.507,72 \mathrm{kWh}$. A soma de intervenções com o vidro GA 120 possibilitou uma redução de $17,1 \%$ no consumo total ao longo de um ano. Substituindo o vidro GA 120 por uma película, a redução pode chegar a $18 \%$.

\subsection{Controle de iluminação artificial para melhor aproveitamento da luz natural}

Segundo Laudares (2007), o projeto de iluminação deve buscar a integração entre luz natural e artificial, com o objetivo de se alcançar edificações energeticamente eficientes. O planejamento dessa integração deve avaliar o balanço da carga térmica nos espaços, com o controle do ofuscamento e com a adequação às variações da disponibilidade de luz natural nos diversos horários do dia e épocas do ano. Dessa forma, buscou-se avaliar e analisar um sistema de controle de iluminação que buscasse diminuir o consumo de energia através da integração de luz natural e artificial.

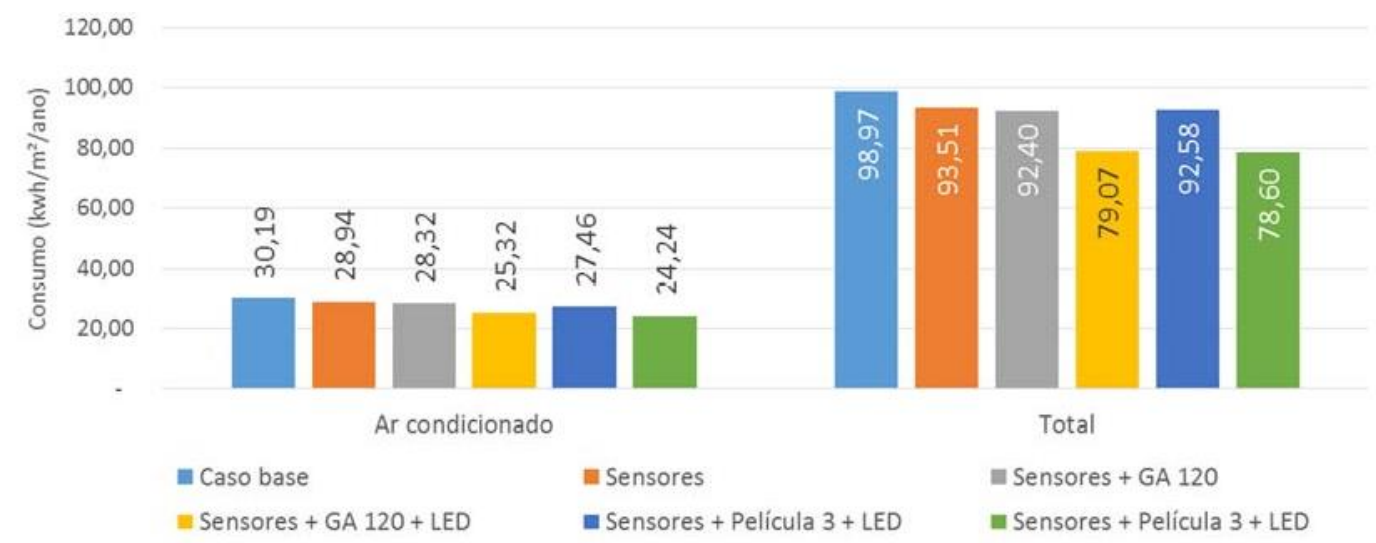


Figura 14 - Consumo de energia atrelado a instalação de sensores de iluminação natural.

Fonte: Elaboração própria utilizando o software Design Builder.

No modelo simulado, o setpoint do sensor foi regulado para manter o nível de iluminação mínimo de 500 lux, ou seja, sempre que a luz natural contribuir com esse grau de iluminância, as lâmpadas estarão operando com ínfima intensidade, diminuído assim o consumo de energia. Cada sensor instalado pode operar até vinte luminárias, consequentemente os dois equipamentos são responsáveis por aproximadamente $15 \%$ da potência total instalada em cada unidade.

Com apenas a implementação dos sensores foi possível atingir uma economia de $4,12 \%$ no consumo do ar condicionado e $5,52 \%$ no consumo total de energia (Figura 14). Agregando-se soluções anteriores como o vidro de melhor performance e lâmpadas LED, atinge-se uma economia de $20,11 \%$ ao ano, equivalente a $245.890,22 \mathrm{kWh}$. Quanto a contribuição da iluminação no consumo, esta cai drasticamente de $360.870,04$ kWh/ano para $176.884,89 \mathrm{kWh} / \mathrm{ano}$.

\section{ANÁLISE DOS RESULTADOS}

O capítulo 5 apresentou os diversos cenários criados através de situações de mercado recorrentes para a melhoria do desempenho energético do estudo de caso. Avaliou-se o impacto de cada solução no que tange o consumo de energia como um todo visando a redução do seu dispêndio. Do ponto de vista da escolha dos cenários, todos se basearam em estratégias factíveis, podendo ser estudados para aplicação em um espaço curto de tempo, sem grandes prejuízos monetários e físicos à operação da edificação e dos locatários que hoje ocupam os conjuntos.

A partir destas definições, montou-se um cenário base com dados pesquisados em normas que regulamentam a calibração de modelos paramétricos de edifícios, manuais e memoriais descritivos fornecidos pelos projetistas, bem como informações levantadas in loco. O consumo de energia das áreas úteis, ou seja, das áreas ocupadas pelos locatários é de 1213,9 kWh/ano, ou 98,97 kWh/m²/ano. Esse resultado está um pouco abaixo da média de consumo dos edifícios em São Paulo verificada por Borgstein e Lamberts (2014) em uma recente pesquisa, a qual apontou um valor de aproximadamente $170 \mathrm{kWh} / \mathrm{m}^{2} /$ ano. Conforme comentado anteriormente, o estudo de caso possui um elevado nível de sombreamento, fator que corrobora com o baixo consumo do ar condicionado, se comparado a outras edificações do mesmo porte.

O primeiro cenário contemplou a substituição dos vidros existentes por outros de melhor desempenho. Com base nas informações dos fabricantes, simulou-se a implementação de materiais com diferentes tecnologias embarcadas. Dos cinco tipos analisados, o modelo GA120 Laminado se mostrou o mais eficiente na redução do consumo de energia total $(0,5 \%)$. Outro aspecto inerente a este material e que deve ser avaliado quando da sua colocação é a transmissão luminosa, aspecto este que impacta diretamente no conforto dos usuários. Por outro lado, as películas se mostraram mais eficientes do que os vidros na atenuação do dispêndio de energia. 0 modelo 3 apresentou uma redução de $2 \%$ no consumo total de energia. A utilização de persianas pouco contribuiu para a melhoria do desempenho energético, porém é um elemento essencial para evitar o ofuscamento próximo as janelas.

Analisando o comportamento da edificação no advento da substituição do sistema de iluminação, nota-se que a influência das lâmpadas com tecnologia LED é vital na performance do estudo de caso. Os resultados da simulação demonstraram que a economia foi de $16,04 \%$ no consumo total anual. Instalando apenas o sistema de controle de iluminação, composto por sensores de iluminação natural, economizou-se 
$5,52 \%$, entretanto combinando outras estratégias concomitantes, é plausível chegar a um abatimento de $20,58 \%$ na despesa energética.

O resultado final desta análise reforça que o levantamento de dados da condição atual do estudo de caso e a calibração do software de simulação termo-energética representam uma etapa importante do trabalho. No entanto, para que os cenários estudados e o aproveitamento das tecnologias existentes sejam incorporados ao edifício existente, deve-se estudar criteriosamente cada estratégia para que o retrofit proposto atenda o seu objetivo principal que é a redução do consumo energético com a incorporação de soluções tecnológicas adequadas.

\section{REFERÊNCIAS}

ASHRAE. ASHRAE Fundamentals. American Society of Heating, Refrigeration and AirConditioning Engineers, Atlanta - EUA, 2009.

BRASIL. EPE; Ministério de Minas e Energia. Balanço Energético Nacional. Brasília, 2014.

BORGSTEIN, Eduardo; LAMBERTS; Roberto, Developing energy consumption benchmarks for buildings: Bank branches in Brazil Energy and Buildings, v.82, p. 8291, 2014.

Copenhagen Economics (CE). Multiple benefits of investing in energy eficient renovation of buildings. Copenhague, Dinamarca, 2012.

GUZENSKI, Fabio. Impacto ambiental del sector de la construcción. Dissertação (Máster en Medio Ambiente y Arquitectura Bioclimática), Universidade Politécnica de Madrid, Madri - Espanha, 2011.

LAUDARES, Daniela; MUELLER, Cecilia. A integração entre luz natural e artificial. Revista Lume. São Paulo, v.28, n.4, p. 28-35, 2007.

MELO, Ana Paula. Avaliação computacional de estratégia para redução do consumo de energia em um hotel de Florianópolis. Dissertação (Graduação em Engenharia Civil), Universidade Federal de Santa Catarina, Florianópolis, 2005.

SANTANA, Marina. Influência de parâmetros construtivos no consumo de energia de edifícios de escritórios localizados em florianópolis. Dissertação (Mestrado em Engenharia Civil), Universidade Federal de Santa Catarina, Florianópolis, 2006.

SERAFIN, Raquel. Avaliação da redução do consumo de Energia Elétrica em Função do Retrofit no Edifício Sede da ELETROSUL. Dissertação (Mestrado em Engenharia Civil), Universidade Federal de Santa Catarina, Florianópolis, 2010.

UNEP. Buildings and Climate Change: Status, Challenges and Opportunities. Paris França, 2007. 